\title{
Prescribing pattern of antibiotics in ENT outpatient department in a tertiary care teaching hospital
}

\author{
Jyothsnya Srinivasa ${ }^{1 *}$, Vijaya Rajendran², Pratibha Nadig ${ }^{2}$, Shubhatara Swamy ${ }^{2}$
}

\author{
${ }^{1}$ Department of Pharmacology, The Oxford Medical College Hospital and Research Centre, Bangalore, Karnataka, \\ India \\ ${ }^{2}$ Department of Pharmacology, Vydehi Institute of Medical Sciences and Research Centre, Bangalore, Karnataka, India
}

Received: 07 July 2020

Revised: 27 October 2020

Accepted: 02 November 2020

\section{*Correspondence:}

Dr. Jyothsnya Srinivasa,

Email: jyothsnya@yahoo.co.in

Copyright: (C) the author(s), publisher and licensee Medip Academy. This is an open-access article distributed under the terms of the Creative Commons Attribution Non-Commercial License, which permits unrestricted non-commercial use, distribution, and reproduction in any medium, provided the original work is properly cited.

\begin{abstract}
Background: Antibiotics are the most commonly used and misused of all drugs. Patterns of antibiotic resistance widely follows local patterns of antibiotic prescribing and usage. Periodic data collection and analysis of antibiotic prescriptions at regional level are essential to understand and combat antibiotic resistance. Objective of the study was to study the prescribing pattern of antibiotics in outpatient department of Otorhinolaryngology in a tertiary care teaching hospital.

Methods: A prospective observational study of prescribing pattern of antibiotics was conducted in the department of Otorhinolaryngology. Data of antibiotic utilization in outpatient department was collected through duplicate copies of the prescriptions. The data obtained was analyzed and the conclusions were drawn using descriptive analysis.

Results: A total of 606 prescriptions were collected and analyzed during the study. Average number of antibiotics prescribed per prescription was 1.24 most of the antibiotics were prescribed for a duration of 1 to 5 days. Commonly prescribed antibiotic class was penicillin $(48.1 \%)$ followed by quinolone $(18.3 \%)$. Most of the antibiotics were prescribed by their brand names $(98.8 \%)$.

Conclusions: The present study highlights the wide use of extended spectrum antibiotics, along with brand names for prescribing. Interventions for prescribing of generic drugs from the essential drug list needs to be encouraged among physicians.
\end{abstract}

Keywords: Antimicrobial usage, Antimicrobial resistance

\section{INTRODUCTION}

Infections remain an important cause of disease, morbidity and mortality among people worldwide, especially among lower income groups. ${ }^{1}$ Upper respiratory tract infections (URTI)s like nasopharyngitis, pharyngitis, tonsillitis and otitis media contribute to 20$40 \%$ of infections among patients attending outpatient departments (OPD). ${ }^{2}$
Several studies on pattern of drug utilization in URTIs highlight the frequent use of antibiotics. ${ }^{3}$ An estimated $80-90 \%$ of the volume of human antibiotics use and antibiotic expenditure $(>60 \%)$ occurs in OPD. ${ }^{4}$ This highlights that a sizeable proportion of antibiotics usage and expenditure occurring in OPD for the treatment of URTIs.

Acute respiratory tract infections are treated using antibiotics. $^{3}$ There is a considerable variation in prescribing of antibiotics in the treatment of URTIs. 
Infecting organism and its susceptibility to antibiotics, host factors and pharmacological factors influence the selection of antibiotics. Factors like prescribing physician choice, patient's condition (e.g., a high-risk or vulnerable patient history), environment (e.g., regulation of pharmaceutical prescribing and dispensing and lack of resources for etiological diagnosis), local policies, treatment guidelines and cost of treatment also influence prescribing of antibiotics. ${ }^{5}$

Use of antibiotics is an important factor in development of antimicrobial resistance (AMR). Pattern of AMR widely follows, the local patterns of antibiotics prescribing and its usage. ${ }^{6}$ Inappropriate and inadequate community prescribing of antibiotics is associated with increase colonization of the infecting organism. Antibiotic selection, appropriateness of use, dose and duration of treatment, infection control measures, cross selection, antibiotic residues, increased industrialization, patient movement and socioeconomic factors also aid in the development and propagation of AMR. ${ }^{7}$ AMR increases the hospital stay, morbidity, mortality and also cost of treatment. ${ }^{8}$

India is among one of the countries with high burden of infectious diseases. ${ }^{9}$ This also contributes to increase consumption of antibiotics especially in the outpatient settings, fueling the development of AMR. ${ }^{10}$ Hence it is imperative to collect data, monitor, evaluate the patterns of antibiotics prescribing and usage periodically from various regions in India. It aids to understand the patterns of microbial susceptibility and resistance to various antibiotics. Available literature in India and abroad bears testimony to the widespread concern about the appropriate use of antibiotics. ${ }^{11-13}$

As antibiotics are commonly prescribed in outpatient setting for upper respiratory tract infections, the present prospective observational study was aimed to evaluate pattern of antibiotics prescribing in Otorhinolaryngology (ENT) outpatient department (OPD) at Vydehi Institute of Medical Sciences and Research Centre, Bangalore.

\section{METHODS}

This study was carried out at outpatient department of ENT at Vydehi Institute of Medical Sciences and Research Centre, Bangalore, after obtaining approval from the Institutional Ethics Committee during May 2011 to June 2011.

Duplicate carbon copies of the prescriptions of patients with at least one antibiotic were collected from the doctors at regular intervals. Prescriptions of follow up, secondary wound infection and readmission patients were excluded from the study. Total of 606 prescriptions were collected and analyzed.

Prescriptions were evaluated based on the world health organization (WHO) core drug prescribing indicators (average number of drugs per prescription, average number of antibiotics per prescription, average duration of antibiotic drug treatment and percentage of antibiotics prescribed by generic name). ${ }^{14}$ Antibiotic prescribing pattern based on the group, route of administration, duration, dosage formulation and fixed dose combinations (FDC) was also analyzed.

The data collected from the prescriptions were fed into Microsoft excel sheet to create a data base file. To analyze the antibiotics and adjuvants prescribed, each drug was assigned a code to obtain the master chart and data was analyzed using descriptive statistics. Results on categorical measurements are presented in number and percentage and was used for generating graphs and tables.

\section{RESULTS}

A total of 606 prescriptions were collected from the ENT OPD and analyzed. $37 \%$ of the prescriptions were prescribed for patients between the age group of 21-30 years, followed by the age group of $31-40$ years $(17.5 \%$ ) (Table 1$) .64 \%$ of prescriptions were prescribed to males in comparison to $36 \%$ prescribed among females (Figure 1).

Table 1: Distribution of prescriptions according to age $(n=606)$.

\begin{tabular}{|l|l|}
\hline Age in years & $\mathbf{N}(\%)$ \\
\hline $\mathbf{1 - 1 0}$ & $66(10.9)$ \\
\hline $\mathbf{1 1 - 2 0}$ & $83(13.7)$ \\
\hline $\mathbf{2 1 - 3 0}$ & $224(37)$ \\
\hline $\mathbf{3 1 - 4 0}$ & $106(17.5)$ \\
\hline $\mathbf{4 1 - 5 0}$ & $65(10.7)$ \\
\hline $\mathbf{5 1 - 6 0}$ & $27(4.5)$ \\
\hline $\mathbf{6 1 - 7 0}$ & $16(2.6)$ \\
\hline $\mathbf{7 1 - 8 0}$ & $1(0.2)$ \\
\hline
\end{tabular}

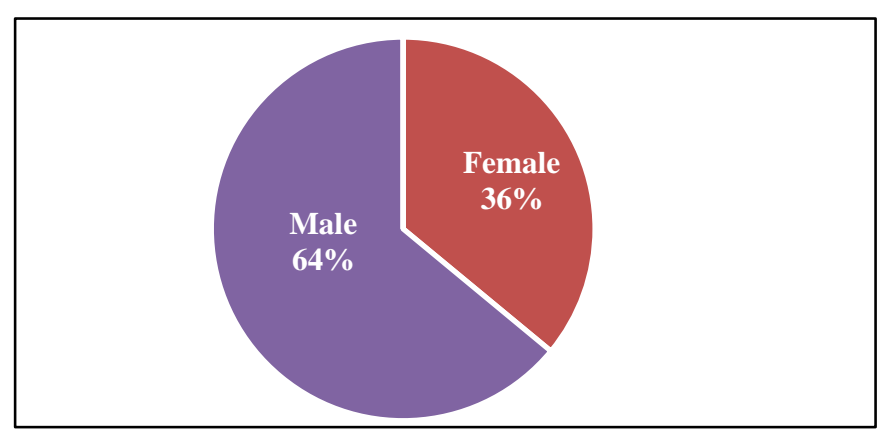

Figure 1: Distribution of prescriptions according to gender.

\section{Analysis of antibiotics prescribed}

Average number of antibiotics prescribed per prescription was 1.23 . In $76.1 \%$ of the patients received a single antibiotic (Table 2). Most of the dosage form were tablets $(46.2 \%)$, followed by capsules $(28.6 \%)$ and topical drops 
(19\%) (Table 3). Commonest route of administration prescribed was oral $(79.3 \%)$ followed by topical application $(20.6 \%)$ and least was intravenous route $(0.8 \%)$ (Figure 2).

Most of the antibiotics were prescribed for 1 to 5 days (Table 4). Commonly prescribed antibiotics belonged to penicillin group $(48.1 \%)$ and quinolones (18.3\%). Topical preparations of polymyxin were also prescribed (Figure 3). Most common prescribed FDC was amoxicillin with clavulanic acid (Table 5). Most of the antibiotics were prescribed by brand name (98.9\%).

Table 2: Distribution of the number of antibiotics prescribed per prescription $(n=606)$.

\begin{tabular}{|ll|}
\hline No of antibiotic per prescription & $\mathbf{N}(\%)$ \\
\hline $\mathbf{1}$ & $461(76.1)$ \\
\hline $\mathbf{2}$ & $143(23.6)$ \\
\hline $\mathbf{3}$ & $2(0.3)$ \\
\hline
\end{tabular}

Table 3: Distribution of dosage formulation of antibiotics prescribed $(n=747)$.

\begin{tabular}{|ll|}
\hline Prescribed dosage form & N $(\%)$ \\
\hline Ointment & $12(1.6)$ \\
\hline Syrup & $28(3.7)$ \\
\hline Drops & $142(19)$ \\
\hline Tablets & $345(46.2)$ \\
\hline Capsules & $214(28.6)$ \\
\hline Injection & $6(0.8)$ \\
\hline
\end{tabular}

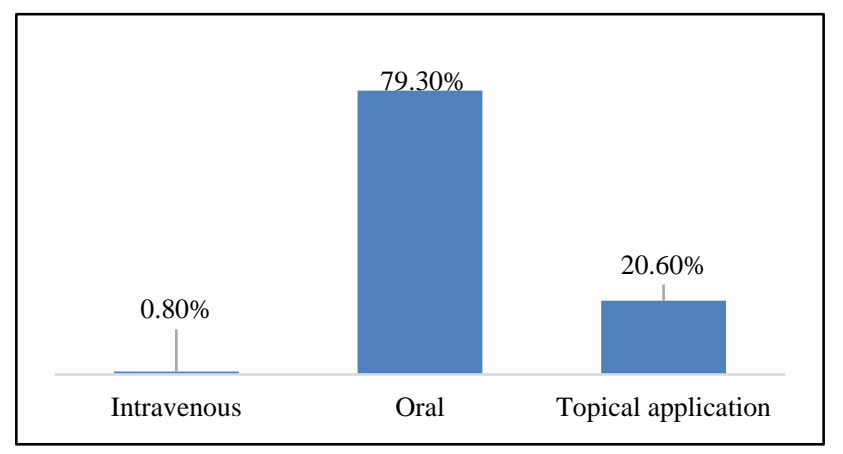

Figure 2: Distribution of antibiotics based on route of administration.

Table 4: Distribution of antibiotics based on duration $(n=747)$.

\begin{tabular}{|ll|}
\hline Duration (days) & $\mathbf{N}(\%)$ \\
\hline $\mathbf{1 - 5}$ & $582(77.9)$ \\
\hline $\mathbf{6 - 1 0}$ & $62(8.2)$ \\
\hline$>\mathbf{1 0}$ & $18(2.4)$ \\
\hline
\end{tabular}

\section{Analysis of adjuvants prescribed}

Average number of drugs prescribed per prescription including antibiotics was 2.7. Of the 606 prescriptions $272(44.9 \%)$ had at least three drugs prescribed (Table 6).
Nasal decongestants were prescribed in $60 \%$ of prescriptions followed by non-steroidal antiinflammatory drugs (NSAIDs) in $22.6 \%$ of prescriptions (Table 7).

Table 5: Distribution of FDCs of antibiotics prescribed $(n=554)$.

\begin{tabular}{|ll|}
\hline FDCs of antibiotics & N $(\%)$ \\
\hline Amoxicillin + clavulanic acid & $240(43.3)$ \\
\hline Ampicillin + cloxacillin & $97(17.5)$ \\
\hline Cefpodoxime + clavulanic acid & $11(1.9)$ \\
\hline Ciprofloxacin + tinidazole & $72(12.9)$ \\
\hline Clotrimoxazole + ofloxacin & $2(0.3)$ \\
\hline Chloramphenicol + clotrimazole & $14(2.5)$ \\
\hline Polymyxin + chloramphenicol & $104(18.7)$ \\
\hline Polymyxin + neomycin + bacitracin & $14(2.5)$ \\
\hline
\end{tabular}

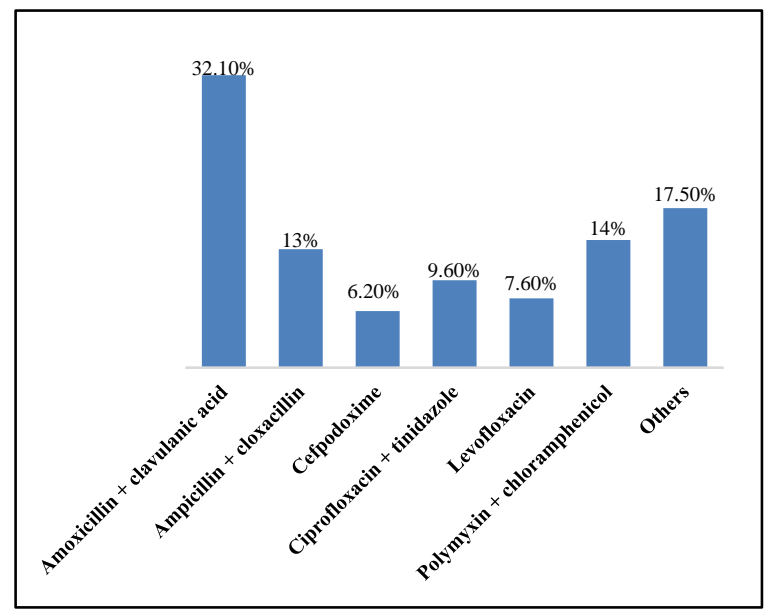

Figure 3: Distribution of antibiotics prescribed.

Table 6: Distribution of the total number of drugs prescribed per prescription $(n=606)$.

\begin{tabular}{|ll|}
\hline No of drugs & $\mathbf{N}(\%)$ \\
\hline $\mathbf{1}$ & $32(5.3)$ \\
\hline $\mathbf{2}$ & $224(37)$ \\
\hline $\mathbf{3}$ & $272(44.9)$ \\
\hline $\mathbf{4}$ & $56(9.2)$ \\
\hline $\mathbf{5}$ & $14(2.3)$ \\
\hline $\mathbf{6}$ & $7(1.2)$ \\
\hline $\mathbf{7}$ & $1(0.2)$ \\
\hline
\end{tabular}

Table 7: Distribution of prescriptions based on the adjuvants prescribed.

\begin{tabular}{|ll|}
\hline Group of adjuvant & Percentage \\
\hline Nasal decongestants & 60.2 \\
\hline NSAIDs & 22.6 \\
\hline Antihistamines & 13.7 \\
\hline Gastric acid secretion inhibitors & 9.2 \\
\hline Nutritional supplements & 8.4 \\
\hline Others & 4.7 \\
\hline
\end{tabular}




\section{DISCUSSION}

Patients belonging the age group of 21-30 and 31-40 years were commonly prescribed antibiotics, and the least number of prescriptions belonged to the geriatric age group, similar to Ain et al. ${ }^{15} 64 \%$ of the prescriptions were prescribed among male patients in comparison $36 \%$ in female patients similar to study by Ain et al, Suman et al. ${ }^{15,16}$ Higher prescriptions among male indicate higher exposure to environmental pollutants and pathogens due to higher ambulatory working adult male population. Frequent visits to the physician by the adult working population shall also result in financial burden. Use of natural gas for cooking and decreased exposure to fumes in the kitchen also contributes to lesser incidence among urban female patients.

\section{Analysis of antibiotics prescribed}

Average number of antibiotics prescribed per prescription was 1.23 including the topical antibiotics which is lower than in the study done by Suman et al. (1.69). ${ }^{16}$ Most commonly prescribed group of antibiotics were penicillins (48.1\%), followed by fluoroquinolones (18.3\%) and cephalosporins $(8.7 \%)$. Combinations of amoxicillin with clavulanic acid was the commonest prescribed antibiotics followed by ampicillin with cloxacillin among the penicillin group. The studies conducted by Suman et al, Khan et al, Bhat et al. have shown that beta lactam antibiotics were the most commonly prescribed antibiotics. ${ }^{16-18}$ This indicates a change in the prescribing patterns from a narrow spectrum to extended spectrum pencillins. Prescribing of extended spectrum penicillins could be due to an increase in antibiotic resistance. Prescribing an extended spectrum antibiotics also increase the cost of treatment. Regular use of levofloxacin (7.6\%) reduces its efficacy when used in the treatment of multi drug resistant Tuberculosis.

Most of the antibiotics were prescribed orally, followed by topical application. Less than $1 \%$ of antibiotics prescribed were injectables similar findings were seen in study done by Padwal et al. ${ }^{19}$ Injections were prescribed in $0.8 \%$ of encounters on average, which was well within the acceptable limit proposed $(\leq 10 \%)$. Increase use of injections fuels the cost of health care management. The study also indicates a substantial use of antibiotics as topical preparations.

\section{Analysis of adjuvants prescribed}

In this study, the average number of drugs per encounter was 2.70 , which is lower than the WHO recommendation of less than 3 drugs per encounter, but indicates a trend towards polypharmacy. ${ }^{14}$ Increase in prescribing errors, drug-drug interaction, adverse drug reactions and cost of treatment increase with increase in number of drugs prescribed per prescription. Similar to Padwal et al NSAIDs were prescribed in $22.6 \%$ of prescriptions. ${ }^{19}$ Similar to the study by Suman et al predominant prescribing of nasal decongestants $(60 \%)$ and antihistamines indicates the need to provide symptomatic relief to patients. ${ }^{16}$ WHO recommends $100 \%$ prescribing by generic name as a safety precaution for patients as it identifies the drug, enables better information exchange and better communication between health care providers. ${ }^{20}$ In the present study only $1.1 \%$ of the drugs were prescribed by generic name, indicating extensive use of brand names. Extensive availability and promotion of branded drugs also increases the prescribing of nongeneric drugs.

$93 \%$ of the drugs are from the National list of essential medicine, India. WHO recommendation of $100 \%$ prescription of drugs from the essential medicines list (EDL). ${ }^{21}$ Prescribing drugs from the EDL issued by WHO provides a framework for rational prescribing. Drugs in EDL are well-established drugs, with established clinical use and lower cost than newer drugs.

\section{CONCLUSION}

The present study measured the drug prescribing pattern in the department of ENT outpatient department using the WHO core drug prescribing indicators. The results showed that the average number of drugs prescribed per encounter and the percentage of encounters with injections prescribed were within the optimal valves proposed. However, the percentage of drugs prescribed by generic name was far from the optimal value. Hence the study recommends interventions to encourage physicians to prescribe generic drugs from the EDL. Future studies are needed to understand the rationality of antibiotics prescribed. Periodic surveillance of antibiotic use regionally with creation of a database shall provide information of the antibiotic usage, antibiotic resistance pattern and also indicate various methods to tackle antibiotic resistance regionally. Involvement of healthcare physicians, health care workers and digitalization of prescribing with feedback, helps in the creating a data base and also in management of antimicrobial resistance aiming to achieve excellent health care to the patients.

\section{ACKNOWLEDGEMENTS}

Authors would like to thank Dr. Manjula Shetty and Dr. Kevin Manohar Salis, for their support during study.

Funding: No funding sources

Conflict of interest: None declared

Ethical approval: The study was approved by the Institutional Ethics Committee

\section{REFERENCES}

1. World Health Organization. Global burden of illness: 2004 update (2008). Available at http://www.who.int/healthinfo/global_burden_diseas e/GBD_report_2004update_part2.pdf. Accessed on 05 June 2019. 
2. Jain N, Lodha R, Kabra SK. Upper respiratory tract infections. Ind J Pediatr. 2001;68:1135-8.

3. Grijalva CG, Nuorti JP, Griffin MR. Antibiotic prescription rates for acute respiratory tract infections in US ambulatory settings. J Am Medic Assoc. 2009;302:758-66.

4. Centers for Disease Control and Prevention. Outpatient antibiotic prescriptions -United States, 2014. Available at https://www.cdc.gov/getsmart/ community/pdfs/annual-reportsummary_2014.pdf. Accessed on 7 June 2019.

5. Calbo E, Rocha L, Gudiol F, Pasquau J. A review of the factors influencing antimicrobial prescribing. Enferm Infecc Microbiol Clin. 2013;31:12-5.

6. Steinkea D, Davey P. Association between antibiotic resistance and community prescribing: a critical review of bias and confounding in published studies. Clin Infect Dis. 2001;33:193-205.

7. Carrie AG, Zhanel GG. Antibacterial use in community practice: assessing quantity, indications and appropriateness, and relationship to the development of antibacterial resistance. Drugs. 1999;57:871-81.

8. Herwaldt LA, Cullen JJ, Scholz D, French P, Zimmerman MB, Pfaller MA, et al. A prospective study of outcomes, healthcare resource utilization and costs associated with postoperative nosocomial infections. Infect Control Hos Epidemiol. 2006;27(12):1291-8.

9. Bassani DG, Kumar R, Awasthi S, Morris SK, Paul VK. Causes of neonatal and child mortality in India: a nationally representative mortality survey. Lancet. 2010;376(9755):1853-60.

10. Goossens H, Ferech M, Stichele R, Elseviers M, Group EP. Outpatient antibiotic use in Europe and association with resistance: a cross-national database study. Lancet. 2005;365(9459):579-87.

11. Bruinsma NS, Grundmann H, Verloo D, Verloo D, Tiemersma E, Monen J, et al. Antimicrobial drug use and resistance in Europe. Emerging Infect Dis. 2008;14(11):1722-30.

12. Peripi SB, Thadepalli VGR, Khagga M, Tripuraribhatla PK, Bharadwai DK. Profile of antibiotic consumption, sensitivity and resistance in an urban area of Andhra Pradesh. India. Singapore Med J. 2012;53(4):268-72.

13. World Health Organization. Global action plan on antimicrobial resistance, 2015. Available at http://www.wpro.who.int/entity/drug_resistance/reso urces/global_action_plan_eng.pdf. Accessed on 08 June 2019.

14. World Health Organisation.How to investigate Drug use in Health Facilities. Selected Drug use Indicators.WHO/DAP/93.1 Geneva: World Health Organisation:1993a. Available at http://www.apps. who.int/medicinedocs/pdf/s2289e.pdf. Accessed on 09 July 2019.

15. Ain MR, Shahzad N, Aqil M, Alam MS, Khanam R. Drug utilization pattern of antibacterials used in ear, nose and throat outpatient and inpatient departments of a university hospital at New Delhi, India. J Pharm Bioallied Sci. 2010;2(1):8-12.

16. Suman RK, Kumar R, Mohanty IR, Deshmukh YA. Assessment of drug usage pattern of antibiotics used in ENT OPD of tertiary care teaching hospital. Int $\mathbf{J}$ Health Sci Res. 2015;5(9):290-7.

17. Khan FA, Nizamuddin S, Tariq SM. Patterns of prescription of antimicrobial agents in the Department of Otorhinolaryngology in a tertiary care teaching hospital. Afr J Pharmacy Pharmacol. 2011;5:1732-8.

18. Bhat GM, Holla R, Kamath PSD. A study of prescription pattern in the drug therapy of ear, nose and throat infections at a tertiary care hospital in Mangalore. Int J Basic Clin Pharmacol. 2015;4:68690.

19. Padwal SL, Kulkarni MD, Deshmukh VS, Patil JR, Jadhav SS, Jadhav AD. Drug use pattern in the ear, nose, throat outpatient department of a rural tertiarycare teaching hospital. Natl J Physiol Pharma Pharmacol. 2015;5:212-6.

20. Guidelines on the use of international nonproprietary names (INNs) for pharmaceutical substances. Geneva, World Health Organization, 1997. Available at http://apps.who.int/medicinedocs/ en/d/Jh1806e/. Accessed on 18 July 2019

21. National list of Essential Medicine (NLEM) 2015. Available at URL:cdsco.nic.in/ NLEM2015/NLEM,\%202015.pdf. Accessed on 09 October 2019.

Cite this article as: Srinivasa J, Rajendran V, Nadig $\mathrm{P}$, Swamy S. Prescribing pattern of antibiotics in ENT outpatient department in a tertiary care teaching hospital. Int J Basic Clin Pharmacol 2020;9:1892-6. 